OPEN ACCESS

Edited by:

Błazej Misiak,

Wroclaw Medical University, Poland

Reviewed by:

Kosuke Kajitani,

Kyushu University, Japan Donghong Cui

Shanghai Mental Health Center

(SMHC), China

*Correspondence:

Milica M. Borovcanin milicaborovcanin@yahoo.com

Specialty section:

This article was submitted to

Psychopharmacology,

a section of the journal

Frontiers in Psychiatry

Received: 15 March 2018

Accepted: 05 June 2018

Published: 22 June 2018

Citation:

Borovcanin MM, Janicijevic SM, Jovanovic IP, Gajovic N, Arsenijevic NN and Lukic ML (2018) IL-33/ST2 Pathway and Galectin-3 as a New Analytes in Pathogenesis and Cardiometabolic Risk Evaluation in

Psychosis. Front. Psychiatry 9:271. doi: 10.3389/fpsyt.2018.00271

\section{IL-33/ST2 Pathway and Galectin-3 as a New Analytes in Pathogenesis and Cardiometabolic Risk Evaluation in Psychosis}

\author{
Milica M. Borovcanin ${ }^{1 *}$, Slavica M. Janicijevic ${ }^{1}$, Ivan P. Jovanovic ${ }^{2}$, Nevena Gajovic ${ }^{2}$, \\ Nebojsa N. Arsenijevic ${ }^{2}$ and Miodrag L. Lukic ${ }^{2}$ \\ ${ }^{1}$ Department of Psychiatry, Faculty of Medical Sciences, University of Kragujevac, Kragujevac, Serbia, ${ }^{2}$ Faculty of Medical \\ Sciences, Center for Molecular Medicine and Stem Cell Research, University of Kragujevac, Kragujevac, Serbia
}

Schizophrenia and treatment of this disorder are often accompanied with metabolic syndrome and cardiovascular issues. Alterations in the serum level of innate immune mediators, such as interleukin-33 (IL-33) and its receptor IL-33R (ST2) and Galectin-3 (Gal-3) were observed in these conditions. Moreover, these parameters are potential prognostic and therapeutic markers. There is also accumulating evidence that these molecules play a role in neuroinflammation. Therefore, in this study we have investigated the serum level of Gal-3, IL-33 and soluble ST2 (SST2) in different stages of schizophrenia. Gal-3 levels were elevated in remission and lower in schizophrenia exacerbation in comparison with controls. Levels of IL-33 and SST2 are higher in schizophrenia exacerbation in comparison with controls and patients in remission. This initial analysis of new markers of neuroinflammation suggested their involvement in schizophrenia pathophysiology and/or cardiometabolic comorbidity.

\section{HIGHLIGHTS}

- Gal-3 serum levels are elevated in remission and lower in schizophrenia exacerbation.

- IL-33 and SST2 serum levels are higher in schizophrenia exacerbation.

- sST2 serum levels negatively correlate with $N$ subscore in acute psychosis.

- sST2 serum levels negatively correlate with cholesterol in relapse and positively with CK-MB in schizophrenia remission.

Keywords: schizophrenia, galectin-3, interleukin-33, metabolic syndrome, cardiovascular issues

\section{INTRODUCTION}

The novel therapeutical strategies have encountered new problems in treatment of patients with schizophrenia (1). Although efficient in resolving the positive symptoms and mitigating the extrapyramidal sympthomatology, the use of atypical antipsychotics in schizophrenia was linked to higher prevalence of patients with metabolic syndrome (2) and cardiovascular issues $(3,4)$. Diagnostic and treatment algorithms incorporated predictive values of Galectin-3 (Gal-3) and interleukin-33 (IL-33) in treatment of coronary diseases and heart failure $(5,6)$ and evaluating prediabetic state (7). The dogma about immune privilege of the brain is now revisited again (8) and this bidirectional communication implicated the usefulness of peripheral markers and indicated that underlying mechanisms of somatic states frequently observed in schizophrenia should be explored further. 
Galectins present animal lectins family, that have the affinity for $\beta$-galactosides and could interact with cell-surface and extracellular matrix glycoproteins through lectin-carbohydrate interactions (9). The most studied and unique family member is Gal-3 (10). Gal-3 is found in different cell and tissue types, and its various functions have been described, like promotion of cell migration, stimulating role in proliferation, differentiation, survival, adhesion, apoptosis, and immune responses (11). Gal-3 can be expressed in cytoplasm, nucleus, mitochondria, and cell surface, and it can also be secreted by macrophages and monocytes and other various cell types into the extracellular matrix and circulation $(12,13)$. Intracellular Gal-3 can be transported to the cell surface or even secreted outside of cells and depending on localization Gal-3 could act as positive or negative regulator of apoptosis [reviewed in (14)]. We postulated that extracellular Gal-3 is most important in interaction that leads to inflammation, as shown in lipopolysaccharide induced neuroinflammation (15). This can be only formally proven by using different inhibitors of Gal-3 in experimental models. Deletion of the Gal-3 gene has influence on deterioration of diabetes mellitus (16) and could predict vascular complications in patients with type 2 diabetes mellitus (17). In obesity in animal models and in humans, elevated serum levels of Gal-3 seem to have protective function (18). Gal-3 showed to be included into myocardial fibrosis and remodeling (19) and circulating Gal-3 was associated with cardiometabolic disease in the community (20).

Experimental studies have shown that Gal-3 gene expression is upregulated after neuronal damage (21), in traumatic spinal cord injury (22) and in experimental autoimmune encephalomyelitis (23). Also, it is expressed in activated adult microglial cells in the ischemic lesion and it is required for resident microglia activation and proliferation (24). Gal-3- deficient mice showed to be protected against ischemic injury, particularly in the hippocampus and striatum (21). Considering Gal-3 regulating properties especially in the hippocampus, Trompet et al. (25) hypothesized that Gal-3 may also play a role in cognitive functioning. Elevated Gal-3 sera levels were measured in patients with Alzheimer's disease and Mini-Mental Status Examination score, as a measure for cognitive status, was found to correlate with the Gal-3 serum levels in both, in the patients and healthy controls (26).

IL-33, as an IL-1 family member, has a role in initiation of inflammation, its regulation and maintenance (27). IL-33 is a ligand for receptor complex of two proteins, binds to ST2 and forms suitable conformation to contact with IL-1 receptor accessory protein. ST2 has two forms: trans-membranes fulllength (ST2L) and soluble form (sST2), which binds directly to IL-33 and has a role as a decoy receptor to competing with membrane bound ST2 (28). It seems that after secreted into the circulation, sST2 inhibits the effects of IL-33/ST2L signaling and attenuates the systemic effects of IL-33 (29). IL-33/ST2 signals have anti- or pro- inflammatory effects in diseases by activating cells of innate and adaptive immune systems, but it is still unclear what kind of immune cells are first induced to produce IL33 (28). IL-33 can have protective properties in atherosclerosis development (30) and blood concentrations of sST2 are markedly increased in cardiac diseases (31) and metabolic syndrome (32).
During the brain development both precursors of astrocytes and oligodendrocytes express IL-33 and its detection during first postnatal week coincides with very important neurodevelopmental phases, suggesting a role of IL-33 in the absence of an inflammatory response (33). Genetic study showed decreased IL-33 expression in the brain of Alzheimer's disease patients (34). IL-33 polymorphism was associated with risk for schizophrenia (35) and recently de Campos-Carli et al. (36) have measured similar sera concentrations of IL-33 and sST2 in patients with chronic schizophrenia and established significant correlation between levels of these cytokines and cognition in chronic schizophrenia.

Consequently, we wanted to investigate the alterations of innate inflammatory markers Gal-3, IL-33, and sST2 in different stages of schizophrenia and to explore the possible correlation of their serum concentrations with clinical symptomatology and laboratory parameter.

\section{EXPERIMENTAL PROCEDURES}

\section{Participants}

Subjects included in this study were: drug naïve patients with First Episode Psychosis-FEP $(n=77)$; patients with Schizophrenia in relapse-SC in relapse $(n=45)$ previously treated with antipsychotics; patients with Schizophrenia in remission-SC in remission $(n=27)$; and healthy control- $\mathrm{HC}$ subjects $(n=18)$. The patients with FEP and SC in relapse were recruited during the previous project [data published in (37-39)] and patients with SC in remission were enrolled during 2016 at Psychiatric Clinic, Clinical Centre Kragujevac, after a 3 month stable depot antipsychotic therapy of risperidone or paliperidone. Healthy control subjects were recruited at Service Supply of Blood and Blood Products, Clinical Centre Kragujevac. Studies were approved by the Ethic Committee and were conducted in compliance with the ethical principles of the Declaration of Helsinki. Patients were informed and written consent was obtained from all of the patients before starting any study procedure.

Diagnoses were established using International Statistical Classification of Diseases and Related Health Problems, Tenth Revision (ICD-10) (40) criteria for acute psychotic episode (F23) and schizophrenia (F20). Complete medical history was obtained; physical examination and laboratory testing were done. The exclusion criteria considered any severe somatic comorbidity, especially current infections, autoimmune disorders, metabolic disorders, or current anti-inflammatory or antiviral medications. Neither the psychotic patients nor controls have previously suffered from substance or alcohol abuse, nor were other mental illnesses diagnosed as dual diagnoses.

\section{Psychological Assessment}

Psychopathology was evaluated using the Positive and Negative Syndrome Scale of Schizophrenia (PANSS) consistent of positive, negative and general psychopathology subscale (41). Criteria for the diagnosis of schizophrenia in remission were lower scores (three or less) on eight diagnostically relevant symptoms in the PANSS: P1, G9, P3, P2, G5, N1, N4, and N6 (42). 


\section{Blood Collection and Cytokine Measurements}

The blood samples were collected in the morning ( $\sim 8$ a.m.) and participants were fasting before sampling. Blood clot was cut, than centrifuged and after separation the serum samples were stored at $-20^{\circ}$. Serum levels of Gal-3, IL-33, and sST2 were measured using sensitive Enzyme-Linked ImmunoSorbent Assay (ELISA) kits specific for the human cytokines, following the instructions of the manufacturer (R\&D System, Minneapolis, $\mathrm{MB}$ ). The procedure has been described in detail previously (3739) and performed at the Center for Molecular Medicine and Stem Cell Research, Faculty of Medical Sciences, University of Kragujevac.

\section{Statistical Analysis}

The data were presented as means, standard deviation (SD), standard errors (SE), and median. The distribution of data was tested with Shapiro-Wilk test and further statistical analysis was performed using parametric and non-parametric tests. MannWhitney test was used to evaluate the significance of differences of parameters between two examined groups. Kruskal-Wallis test was used to examine the difference of parameters among groups. The possible relationships between patients' serum cytokine levels and clinical scores were evaluated using the Pearson's correlation and between laboratory parameters and clinical scores using the Spearman's correlation. A $p$-value of 0.05 was considered to be statistically significant. The statistical analyses were performed using SPSS 20.0 software.

\section{RESULTS}

\section{Demographical and Clinical Data}

The control group consisted of 18 healthy subjects (6 men vs. 12 women), with mean age of $37.67 \pm 9.96$ and without significant age difference in comparison with patients' groups. Table 1 presents demographic and clinical characteristics of the patients. Significant difference was observed in duration of illness among groups of patients, showed in Table 1 (FEP vs. SC in relapse vs. SC in remission: $0.28 \pm 1.93$ vs. $7.31 \pm 6.30$ vs. $9.95 \pm$ 7.71 years; $p=0.000$ ), with no difference in gender distribution comparing with control group. Comparison of PANSS scores and subscores reveals differences in positive, negative and general psychopathology scores between patients. Mean value of negative subscores was higher in SC in relapse, than those in FEP patients (FEP vs. SC in relapse: $21.75 \pm 5.90$ vs. $26.20 \pm 9.98$; $p=0.006$ ). Patients with SC in remission have significantly lower positive and general subscores $(p=0.007$ and $p=0.004$, respectively), with higher negative subscores $(p=0.000)$ than patients with FEP. Differences in PANSS subscores were established in lower positive $(p=0.007)$ and lower general subscores $(p=0.001)$ in patients with SC in remission compared with SC patients in relapse.

Patients with SC in remission were treated with depot formulation of atypical antipsychotics risperidone in a dose range of $25-50 \mathrm{mg}\left(\sum n=22\right)$ and paliperidone in a dose range of $75-$ $150 \mathrm{mg}\left(\sum n=5\right)$. Laboratory analysis parameters are presented in Table 2.

\section{Higher Serum Concentrations of IL-33 and sST2 in Exacerbation of Early Schizophrenia}

Comparison of IL-33 serum levels between FEP and SC in relapse group did not reveal statistically significant difference $(p=0.869)$. Also, there was no difference in serum levels of IL33 between SC in remission and HC subjects $(p=0.871)$. IL-33 sera levels were significantly higher in FEP patients compared to SC in remission and those in HC (FEP vs. SC in remission vs. HC: $470.97 \pm 72.54$ vs. $89.61 \pm 40.48$ vs. $188.35 \pm 85.64 \mathrm{pg} / \mathrm{ml}$; $p=0.000$ ). Comparing serum concentrations of IL-33 in SC in relapse with those in remission and $\mathrm{HC}$ also show statistically significant difference ( $p=0.000$ and $p=0.001$, respectively) (Figure 1).

While conducting the group cross-comparison of serum sST2 levels, the grading in descending manner was observed (Figure 1). The statistically significant higher values of sST2 were measured in patients with FEP compared to SC in relapse $(3648.26 \pm 130.34$ vs. $3030.19 \pm 183.08 \mathrm{pg} / \mathrm{ml} ; p=0.010)$, higher values were observed in patients with SC in relapse compared with SC in remission (3030.19 \pm 183.08 vs. 936.03 $\pm 66.82 \mathrm{pg} / \mathrm{ml} ; p=0.000$ ), with no difference between serum levels of sST2 in patients with SC in remission and healthy control group $(936.03 \pm 66.82$ vs. $845.27 \pm 55.96$; $p=0.391)$.

\section{Correlations of IL-33 Serum Levels With Positive and General PANSS Scores}

Sera levels of IL-33 in remission are in significant correlation with the PANSS items of positive symptoms [excitement P4 $(r=0.570 ; p=0.002)$, suspiciousness/persecution - P6 $(r=0.486 ; p=0.010)$, and hostility - P7 $(r=0.664$; $p=0.000)$ ] and general symptoms [anxiety - G2 $(r=0.424$; $p=0.028)$, tension - G4 $(r=0.435 ; p=0.023)$, and uncooperativeness - G8 $(r=0.396 ; p=0.041)]$ (presented in Figure 2).

\section{Serum Concentrations of Gal- 3 in Patients With Schizophrenia Are Lower in Exacerbation and Higher in Remission Compared With Healthy Subjects}

Levels of Gal-3 in patients with FEP and SC in relapse were not significantly different between these groups of patients (297.52 \pm 37.86 vs. $252.75 \pm 41.35 \mathrm{pg} / \mathrm{ml} ; p=0.230$ ), but lower levels were measured in both groups compared with those in $\mathrm{HC}(p=0.000)$ (Figure 3). In patients with SC in remission significantly higher levels of Gal-3 were observed in comparison with concentrations measured in patients with FEP $(1457.89 \pm 104.60$ vs. $297.52 \pm$ $37.86 \mathrm{pg} / \mathrm{ml} ; p=0.000)$, $\mathrm{SC}$ in relapse $(1457.89 \pm 104.60$ vs. $252.75 \pm 41.35 \mathrm{pg} / \mathrm{ml} ; p=0.000)$, and $\mathrm{HC}(1457.89 \pm 104.60$ vs. $1044.28 \pm 83.37 \mathrm{pg} / \mathrm{ml} ; p=0.011)$. Binary logistic regression analysis revealed that increased levels of Gal-3 influence on the illness onset [Odds Ratio 0.998 (0.996-1.000)]. There was no correlation between Gal-3 sera levels with positive, negative, general and total PANSS scores (data not presented). 
TABLE 1 | Demographic data and clinical disability measures.

\begin{tabular}{|c|c|c|c|c|c|c|c|c|}
\hline Parameter & $\begin{array}{l}\text { Gen } \\
\text { Mer }\end{array}$ & nen & $\begin{array}{l}\text { Age } \\
\text { (Years; mean } \\
\pm S D \text { ) }\end{array}$ & $\begin{array}{l}\text { Duration of illness } \\
\text { (Years; mean } \pm \text { SD) }\end{array}$ & $\begin{array}{l}\text { PANSS } \\
\text { positive } \\
\text { score }\end{array}$ & $\begin{array}{l}\text { PANSS } \\
\text { negative } \\
\text { score }\end{array}$ & $\begin{array}{l}\text { PANSS } \\
\text { general } \\
\text { score }\end{array}$ & $\begin{array}{l}\text { PANSS } \\
\text { total } \\
\text { score }\end{array}$ \\
\hline FEP & 36 & 52 & $33.64 \pm 8.84$ & $0.28 \pm 1.93$ & $25.73 \pm 5.99$ & $21.75 \pm 5.90$ & $53.56 \pm 7.27$ & $101.03 \pm 14.62$ \\
\hline $\mathrm{SC}$ in relapse & 17 & 28 & $35.95 \pm 11.40$ & $7.31 \pm 6.30$ & $26.53 \pm 6.29$ & $26.20 \pm 9.98^{\star}$ & $56.44 \pm 12.67$ & $105.86 \pm 19.79$ \\
\hline $\mathrm{SC}$ in remission & 11 & 16 & $36.19 \pm 9.28$ & $9.95 \pm 7.71$ & $22.26 \pm 5.97^{\star \star \star \star \star \star \star}$ & $27.52 \pm 6.10^{\star \star}$ & $9.44 \pm 7.83^{\star \star, \star \star \star}$ & $99.22 \pm 18.24$ \\
\hline
\end{tabular}

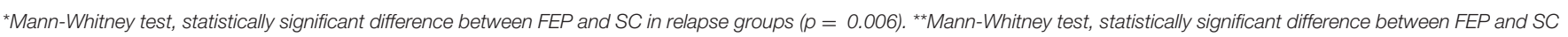
in remission groups $(p<0.05)$. ${ }^{* \star *}$ Mann-Whitney test, statistically significant difference between SC in relapse and SC in remission groups ( $\left.p<0.05\right)$.

TABLE 2 | Laboratory values of cardiometabolic parameters.

\begin{tabular}{|c|c|c|c|c|c|c|c|}
\hline Parameter & $\begin{array}{l}\text { Fasting } \\
\text { glucose } \\
(\mathrm{mMol} / \mathrm{L})\end{array}$ & $\begin{array}{l}\text { Total } \\
\text { cholesterol } \\
\text { (mMol/L) }\end{array}$ & $\begin{array}{l}\text { Triglycerides } \\
\text { (mMol/L) }\end{array}$ & $\begin{array}{l}\text { HDL } \\
\text { (mMol/L) }\end{array}$ & $\begin{array}{l}\text { LDL } \\
\text { (mMol/L) }\end{array}$ & $\begin{array}{l}\text { CK } \\
\text { (IU/L) }\end{array}$ & $\begin{array}{l}\text { CK-MB } \\
\text { (IU/L) }\end{array}$ \\
\hline FEP & $5.04 \pm 1.38$ & $5.17 \pm 2.97$ & $3.60 \pm 2.15$ & $1.35 \pm 0.42$ & $2.89 \pm 1.21$ & $437.46 \pm 1275.16$ & $N^{a}$ \\
\hline $\mathrm{SC}$ in relapse & $5.01 \pm 2.10$ & $4.86 \pm 1.37$ & $1.32 \pm 1.03$ & $1.33 \pm 0.38$ & $3.33 \pm 2.35$ & $533.10 \pm 1346.93$ & $\mathrm{ND}^{\mathrm{a}}$ \\
\hline SC in remission & $5.27 \pm 2.14$ & $5.90 \pm 1.38$ & $1.80 \pm 1.31$ & $1.34 \pm 0.31$ & $3.66 \pm 1.14$ & $119.33 \pm 92.82$ & $19.19 \pm 4.26$ \\
\hline
\end{tabular}

${ }^{a} N D$, not done.

\section{Correlation of Serum sST2 With Negative Scores, Cholesterol and Cardiac Troponin Levels}

In patients with acute psychosis, sera levels of sST2 were in negative correlation with $\mathrm{N}$ subscore $(r=-0,184 ; p=0.044)$ and in patients with SC in remission sera levels were in positive correlation with item P7 $(r=0.413 ; p=0.032)$, stereotyped thinking - N7 $(r=0.384 ; p=0.048)$. In patients with schizophrenia in remission negative correlation was observed between serum concentrations of sST2 and levels of cholesterol $(r=-0.434 ; p=0.024)$, Low-Density Lipoprotein (LDL) $(r=-0.479 ; p=0.011)$ and positive correlation with Creatine Kinase - MB (CK-MB) levels $(r=0.460 ; p=0.016)$.

\section{DISCUSSION}

In this study we evaluated the serum level of two novel participants in innate immunity in patients with psychosis. We have shown that Gal-3 levels were lower in FEP and SC in relapse and higher in SC in remission than those measured in control subjects. We observed higher serum levels of IL-33 and sST2 in patients with FEP and SC in relapse, compared with those in remission and healthy control subjects. In remission, the positive correlation of sera levels of IL-33 was established with positive symptoms of excitement, suspiciousness/persecution, and hostility, but also with general symptoms of anxiety and tension. Serum level of sST2 in acute psychosis negatively correlated with $\mathrm{N}$ subscore, but in remission correlated positively with hostility and stereotyped thinking. Measurements in remission reveal the negative correlation of sST2 levels with cholesterol and LDL levels, but positive correlation with cardiac troponin CK-MB was observed.
There is clear importance of Gal-3 in development of nervous system and in neuroinflammation. Gal-3 plays a role in the modulation of immune/inflammatory function, with both proand anti-inflammatory actions, depending on multiple factors, such as inflammatory setting and target cell/tissue $(11,43,44)$. It is well known that Gal-3 regulation of type-1/type-2 immune response in asthma was presented with lower airway type- 2 response in Gal-3 ${ }^{-/-}$, but a higher type-1 response compared to Gal-3 ${ }^{+/+}$mice, indicating that Gal-3 facilitates type 2 immune response (45). Also, asthma and schizophrenia cooccurrence was established $(46,47)$. Kajitani et al. (48) recently reported that the serum Gal-3 levels are elevated in chronic schizophrenia. Thus, it is not surprising to find lower level of Gal-3 in patients with FEP and SC in relapse and higher level in SC in remission (Figure 3) and it is in line with our previous finding of type-2 immune response predominance in these patients (37). We believe that Gal-3 acts as a proinflammatory lectin in patients with schizophrenia. Further, elevation of Gal3 in chronic schizophrenia could initiate myocardial fibrosis, metabolic changes, and may have protective properties in type2 diabetes. Gal-3 could be a mediator of underlying mechanisms in schizophrenia onset and cardiovascular and metabolic changes in these patients.

We have shown here that the level of IL-33 is not significantly altered in schizophrenia patients in remission (Figure 1). However, there is clear statistically significant increase in IL-33 levels in patients with exacerbation (Figure 1) and correlation of its levels with positive symptoms scores (Figure 2). Earlier studies have shown different role of IL-33 in inflammatory diseases; immunosupressive role in obesity, atherosclerosis and experimental fulminant hepatitis and proinflammatory role in asthma and antigen-induced arthritis (49-51). Although, IL-33 was initially considered to be a proinflammatory cytokine, its 
A

\begin{tabular}{|c|c|c|c|c|}
\hline $\begin{array}{c}\text { cytokine } \\
\text { concentrations } \\
(\mathrm{pg} / \mathrm{ml} ; \\
\text { mean } \pm \text { SE) }\end{array}$ & FEP & SC in relapse & $\begin{array}{c}\text { SC in } \\
\text { remission }\end{array}$ & HC \\
\hline IL-33 & $470.97 \pm 72.54$ & $420.54 \pm 80.12$ & $89.61 \pm 40.48$ & $188.35 \pm 85.64$ \\
\hline $\mathbf{s S T 2}$ & $3648.26 \pm 130.34$ & $3030.19 \pm 183.08$ & $936.03 \pm 66.82$ & $845.27 \pm 55.96$ \\
\hline
\end{tabular}

B

IL-33

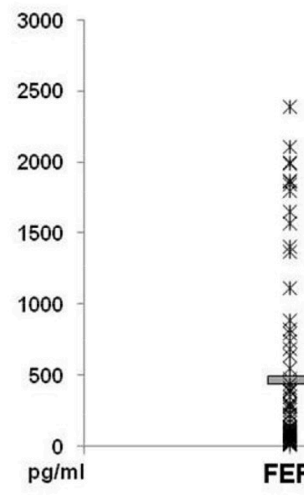

C

\section{sST2}

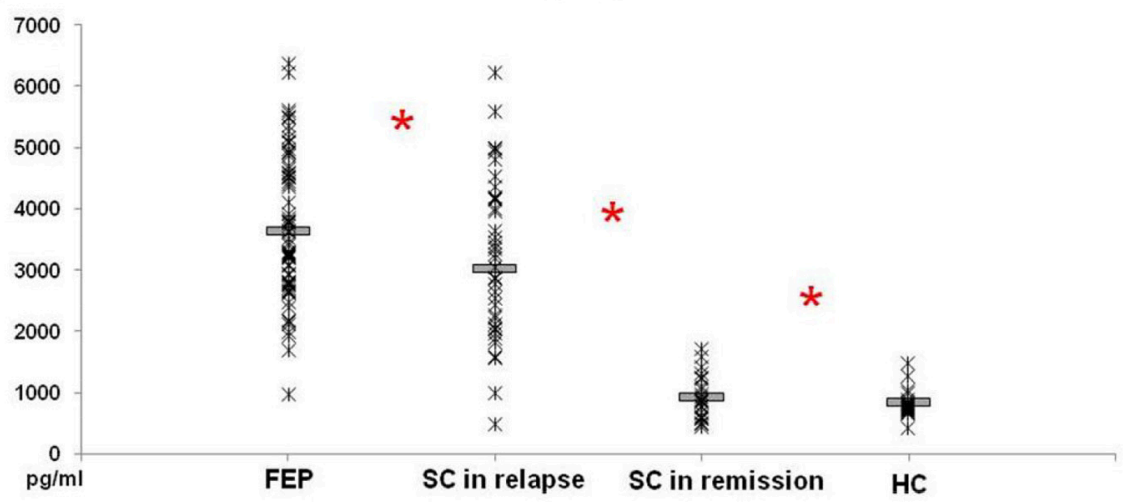

FIGURE 1 | Serum levels of IL-33 and SST2 in FEP patients $(n=77)$, SC in relapse $(n=45)$, SC in remission $(n=27)$ and healthy subjects $(n=18)$ were determined by ELISA. Data presented as mean \pm SE in Table (A). Statistical significance was tested by Kruskal-Wallis and Mann-Whitney test ( $\left.{ }^{*} p<0.05\right)$. Serum concentrations of IL-33 were higher in FEP and SC in relapse, than SC in remission and healthy control subjects $(p \leq 0.001)$ (B). Serum concentrations of sST2 were higher in patients with FEP compared to SC in relapse, than higher values were observed in patients with SC in relapse compared with SC in remission ( $p \leq 0.01)$ and $\mathrm{SC}$ in remission than control subjects (C).

linkage with regulatory $\mathrm{T}$ (Treg) immune response was later suggested (51). Recent data have shown that IL-33 downregulates immune response in autoimmune processes (52). It is well known that IL-33 is abundantly present in the central nervous system (CNS) (53). It is particularly highly expressed during early development (33), as well as in inflammatory disease in CNS such as experimental autoimmune encephalitis, an animal model of multiple sclerosis (54). Also, it is reported that IL-33 can modulate microglia in an animal model of Alzheimer's disease (55), but its function in these condition is still unclear. It is established that IL-33 acts as alarmin, meaning that this cytokine is released from cells during tissue damage, and not apoptotic cells (56). We assume that during CNS damage, neuroinflammation is followed by IL-33 release from necrotic cells and increment of its serum levels in patients with schizophrenia. It should be added that in atherosclerosis, IL-33 was protective (30). Thus, it is possible that IL-33 production is an attempt to limit inflammation accompanying relapse in schizophrenia. However, direct pathogenic effect cannot be excluded as ST2 dependent Th2 pathology reported to be common denominator in asthma and schizophrenia (57). Considering that sST2 binds directly to IL-33 or acts as a decoy 

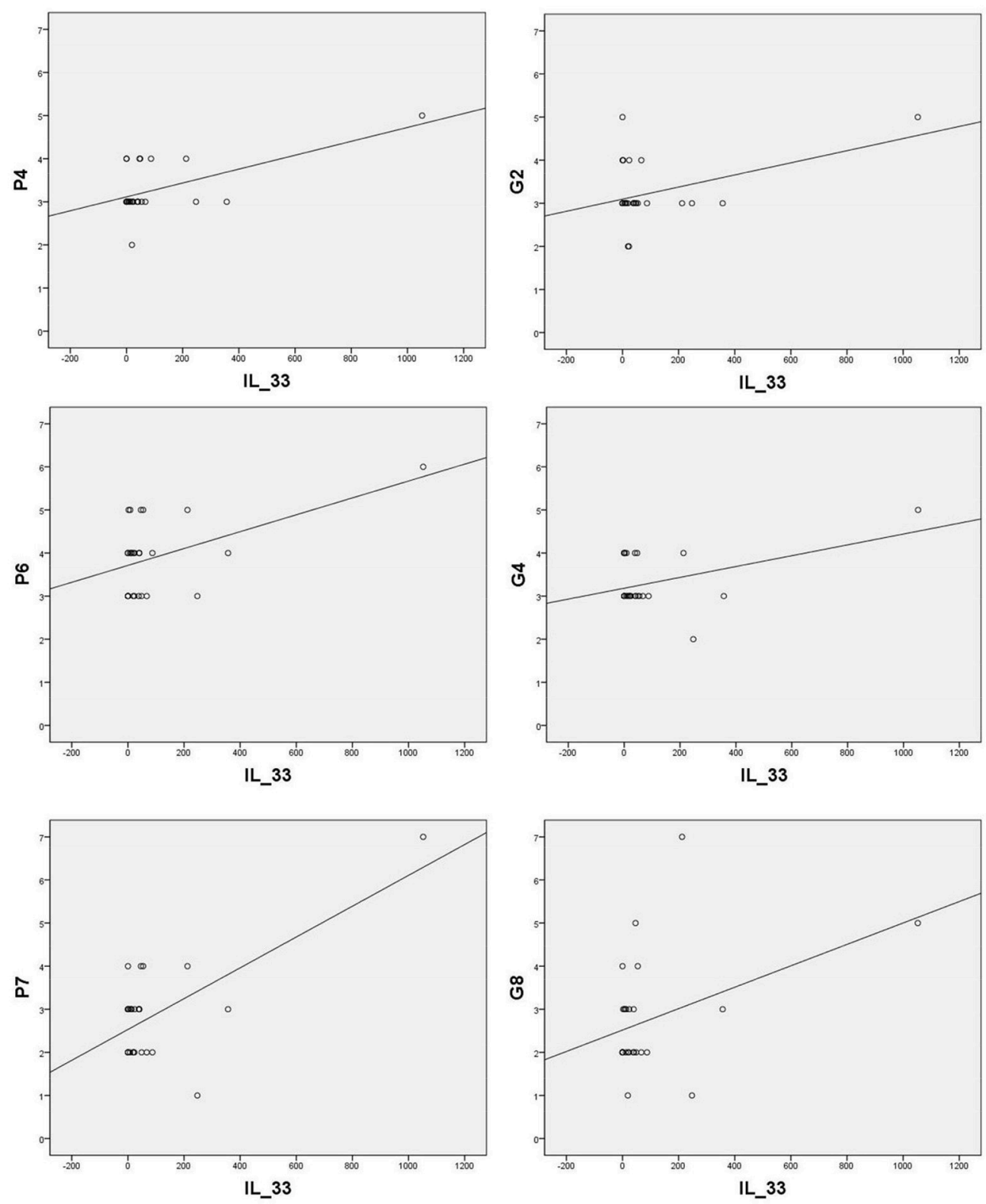

FIGURE 2 | Significant correlation of IL-33 with positive PANSS items [P4 ( $r=0.570 ; p=0.002), \mathrm{P} 6(r=0.486 ; p=0.010), \mathrm{P} 7(r=0.664 ; p=0.000)]$ and general PANSS symptoms [G2 ( $r=0.424 ; p=0.028)$, G4 $(r=0.435 ; p=0.023)$ and $\mathrm{G} 8(r=0.396 ; p=0.041)]$.

receptor when competing with membrane bound ST2 [reviewed in (28)], higher systemic level of sST2 in FEP and SC patients in relapse as well as negative correlation of this molecule with $\mathrm{N}$ subscore in acute psychosis may represent compensatory mechanism in suppressing IL-33-dependent inflammation.

The positive correlation of IL-33 with positive PANSS symptoms in remission suggests its potential role in underling mechanisms of psychosis onset. sST2 could have neutralizing properties in the context of excessive IL-33 secretion and also in amelioration of negative symptoms. Although direct correlation of Gal-3 levels with clinical symptoms was not established, some other molecular mechanisms involved in Gal-3-dependent regulation could preserve cognitive potentials in patients with schizophrenia. Considering involvement of Gal-3 and the IL33/ST2 pathway interactions in the somatic states (58), this interplay could be also involved in onset, clinical presentation and somatic comorbidity of psychosis.

As discussed by Mueller and Dieplinger (59), plasma concentrations of these two analytes have been incorporated in $2013 \mathrm{ACCF} / \mathrm{AHA}$ guidelines for additive risk stratification in acute and chronic heart failure (60) and Gal-3, sST2 and BNP were all useful as predictors of 1-year all-cause mortality 


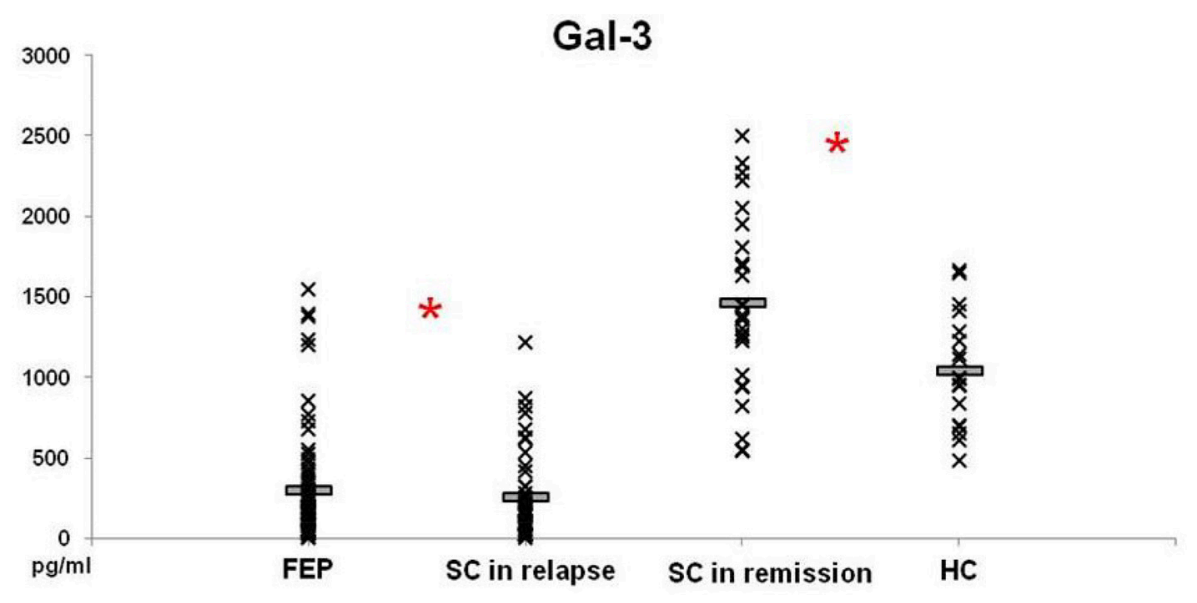

FIGURE 3 | Serum levels of Gal-3 in FEP patients ( $n=77)$, SC in relapse ( $n=45)$, SC in remission $(n=27)$ and healthy subjects $(n=18)$ were determined by ELISA. Data presented as mean \pm SE. Statistical significance was tested by Kruskal-Wallis and Mann-Whitney test $\left({ }^{*} p<0.05\right)$. Serum concentrations of Gal-3 were significantly lower in FEP and SC in relapse groups and higher in SC in remission, compared with group of healthy control subjects.

(6). It was previously presented that life expectancy of patients with schizophrenia is $10-25$ years shorter than in general population (61) and $40-50 \%$ of premature deaths have been due to cardiovascular diseases (62). Patients with schizophrenia are reported to be three times as likely to experience sudden cardiac death (63). Hou et al. (4) have shown that a history of aggressive behaviors is strongly associated with sudden cardiac death in patients with schizophrenia. Although CK-MB levels were measured additionally only in stable state in our study, in spite of that, the positive correlation with serum sST2 was established. Simultaneously presented elevation of sST2 and higher scores on items equivalent of aggressive behavior suggest that these new inflammatory markers should be considered in additional monitoring of cardiac symptoms that occur without warning in schizophrenia.

Innate immune system primarily initiates defense against pathogens, but also contributes to adaptive induction of sickness behavior and infection recovery (64). In the previous few years central nervous system was no longer viewed as an immunologicaly isolated space, but it seems that its dynamic interaction with the peripheral immune system regulates the activity of immune cells within the central nervous system (65). Childhood traumatic events could have a significant impact by changing the immune response and precipitating further vulnerability for psychiatric disorders and somatic states later in life (64). It is now obvious that metabolic dysregulation in patients with schizophrenia already exists before antipsychotic treatment $(66,67)$. The fact that schizophrenia risk is driven by genes that not have direct relevance to disease, suggests that schizophrenia could rather be considered as developmental physiological defect (68).

\section{THE LIMITATIONS OF THE STUDY}

The sample size of the healthy control subjects is rather small compared to other groups (FEP, SC in relapse). The data considering potential confounding factors, such as body mass index, cigarette smoking, and the use of alcohol or other illicit drugs were not collected in patients with FEP and SC in relapse, so it was not possible to include these data into assessment. The possible impact of antipsychotics on cytokine profiles could not be excluded (69), so the further analysis of diverse antipsychotics" influences on these specific biomarkers should be done.

\section{CONCLUSIONS}

The study of two pathways of innate immunity in schizophrenia revealed that the serum levels of IL-33 and its soluble receptor was unaltered in stable disease, but was significantly enhanced in exacerbation and accompanied with hostility and elevation of cardiac troponin levels. Further, Gal-3 is increased in the serum of schizophrenia patients in remission and seems to be involved in schizophrenia onset. Taken together, this initial analysis of new markers of inflammation suggested their involvement in schizophrenia pathogenesis and cardiometabolic comorbidity.

\section{AUTHOR CONTRIBUTIONS}

All authors equally contributed in the planning, designing and conducting this research. MB and SJ selected the patients, did psychological assessment and statistical analysis and wrote about psychiatric aspects of this topic. IJ, NG, MB, and SJ have done cytokine measurements. $\mathrm{MB}$ and IJ designed figures and tables. IJ and NG wrote about immunological underlying mechanisms. NA and ML wrote the introduction and discussion and made integral version of the manuscript. All authors approved the final manuscript.

\section{FUNDING}

This work was supported by grants from the Ministry of Science and Technological Development of Republic of Serbia 
(projects 175103 and 175069) and from the Faculty of Medical Sciences, University of Kragujevac (project JP 12-09 and JP 15-05).

\section{REFERENCES}

1. American Diabetes Association, American Psychiatric Association, American Association of Clinical Endocrinologists, North American Association for the Study of Obesity. Consensus development conference on antipsychotic drugs and obesity and diabetes. Diabetes Care (2004) 27:596-601. doi: $10.2337 /$ diacare.27.2.596

2. Mitchell AJ, Vancampfort D, Sweers K, van Winkel R, Yu W, De Hert M. Prevalence of metabolic syndrome and metabolic abnormalities in schizophrenia and related disorders - a systematic review and meta-analysis. Schizophr Bull. (2013) 39:306-18. doi: 10.1093/schbul/sbr148

3. Fan Z, Wu Y, Shen J, Ji T, Zhan R. Schizophrenia and the risk of cardiovascular diseases: a meta-analysis of thirteen cohort studies. J Psychiatr Res. (2013) 47:1549-56. doi: 10.1016/j.jpsychires.2013.07.011

4. Hou PY, Hung GC, Jhong JR, Tsai SY, Chen CC, Kuo CJ. Risk factors for sudden cardiac death among patients with schizophrenia. Schizophr. Res. (2015) 168:395-401. doi: 10.1016/j.schres.2015.07.015

5. Berezin AE. Cardiac biomarkers in diabetes mellitus: new dawn for risk stratification? Diabetes. Metab. Syndr. (2016) 11(Suppl. 1):S201-8. doi: 10.1016/j.dsx.2016.12.032

6. Mueller T, Gegenhuber A, Leitner I, Poelz W, Haltmayer M, Dieplinger B. Diagnostic and prognostic accuracy of galectin-3 and soluble ST2 for acute heart failure. Clin Chim Acta. (2016) 463:158-64. doi: 10.1016/j.cca.2016.10.034

7. Yilmaz H, Cakmak M, Inan O, Darcin T, Akcay A. Increased levels of galectin3 were associated with prediabetes and diabetes: new risk factor? J Endocrinol Invest. (2015) 38:527-33. doi: 10.1007/s40618-014-0222-2

8. Louveau A, Smirnov I, Keyes TJ, Eccles JD, Rouhani SJ, Peske JD, et al. Structural and functional features of central nervous system lymphatic vessels. Nature (2015) 523:337-41. doi: 10.1038/nature14432

9. Dumic J, Dabelic S, Flögel M. Galectin-3: an open-ended story. Biochim Biophys Acta. (2006) 1760:616-35. doi: 10.1016/j.bbagen.2005.12.020

10. Funasaka T, Raz A, Nangia-Makker P. Galectin-3 in angiogenesis and metastasis. Glycobiology (2014) 24:886-91. doi: 10.1093/glycob/cwu086

11. Radosavljevic G, Volarevic V, Jovanovic I, Milovanovic M, Pejnovic N, Arsenijevic N, et al. The roles of Galectin-3 in autoimmunity and tumor progression. Immunol Res. (2012) 52:100-10. doi: 10.1007/s12026-012-8286-6

12. Yu F, Finley R, Raz A, Kim HRC. Galectin-3 translocates to the perinuclear membranes and inhibits cytochrome $c$ release from the mitochondria. A role for synexin in galectin-3 translocation. J. Biol. Chem. (2002) 277:15819-27. doi: 10.1074/jbc.M200154200

13. Shibata T, Noguchi T, Takeno S, Takahashi Y, Fumoto S, Kawahara K. Impact of nuclear galectin-3 expression on histological differentiation and vascular invasion in patients with esophageal squamous cell carcinoma. Oncol. Rep. (2005) 13:235-9. doi: 10.3892/or.13.2.235

14. Radosavljevic G, Pantic J, Jovanovic I, Arsenijevic N, Lukic ML. The two faces of galectin-3: roles in various pathological conditions. Ser J Exp Clin Res. (2016) 17:187-98. doi: 10.1515/sjecr-2016-0011

15. Yip PK, Carrillo-Jimenez A, King P, Vilalta A, Nomura K, Chau CC, et al. Galectin-3 released in response to traumatic brain injury acts as an alarmin orchestrating brain immune response and promoting neurodegeneration. Sci Rep. (2017) 7:41689. doi: 10.1038/srep41689

16. Mensah-Brown EP, Al Rabesi Z, Shahin A, Al Shamsi M, Arsenijevic N, Lukic $\mathrm{ML}$, et al. Targeted disruption of the galectin-3 gene results in decreased susceptibility to multiple low dose -induced diabetes in mice. Clin Immunol. (2009) 130:83-8. doi: 10.1016/j.clim.2008.08.024

17. Jin QH, Lou YF, Li TL, Chen HH, Liu Q, He XJ. Serum galectin-3: a risk factor for vascular complications in type 2 diabetes mellitus. Chin. Med. J. (2013) 126:2109-15. doi: 10.3760/cma.j.issn.0366-6999.20130217

18. Pejnovic NN, Pantic JM, Jovanovic IP, Radosavljevic GD, Milovanovic MZ, Nikolic IG, et al. Galectin-3 deficiency accelerates high-fat diet-induced

\section{ACKNOWLEDGMENTS}

We thank Aleksandar Ilic for excellent technical assistance. obesity and amplifies inflammation in adipose tissue and pancreatic islets. Diabetes (2013) 62:1932-44. doi: 10.2337/db12-0222

19. Gawor M, Spiewak M, Janas J, Kozuch K, Wróbel A, Mazurkiewicz Ł, Grzybowski J, et al. The usefulness of sST2 and galectin-3 as novel biomarkers for better risk stratification in hypertrophic cardiomyopathy. Kardiol. Pol. (2017) 75:997-1004. doi: 10.5603/KP.a2017.0118

20. Nayor M, Wang N, Larson MG, Vasan RS, Levy D, Ho JE. Circulating galectin3 is associated with cardiometabolic disease in the community. J Am Heart Assoc. (2015) 5:e002347. doi: 10.1161/JAHA.115.002347

21. Doverhag C, Hedtjärn M, Poirier F, Mallard C, Hagberg H, Karlsson A, et al. Galectin-3 contributes to neonatalhypoxic-ischemic brain injury. Neurobiol Dis. (2010) 38:36-46. doi: 10.1016/j.nbd.2009.12.024

22. Pajoohesh-Ganji A, Knoblach SM, Faden AI, Byrnes KR. Characterization of inflammatory gene expression and galectin-3 function after spinal cord injury in mice. Brain Res. (2012) 1475:96-105. doi: 10.1016/j.brainres.2012.07.058

23. Reichert F, Rotshenker S. Galectin-3/MAC-2 in experimental allergic encephalomyelitis. Exp Neurol. (1999) 160:508-14. doi: 10.1006/exnr.1999.7229

24. Lalancette-Hébert M, Swarup V, Beaulieu JM, Bohacek I, Abdelhamid E, Weng YC, et al. Galectin-3 is required for resident microglia activation and proliferation in response to ischemic injury. Kriz J J Neurosci. (2012) 32:10383-95. doi: 10.1523/JNEUROSCI.1498-12.2012

25. Trompet S, Jukema W, Mooijaart SP, Ford I, Stott DJ, Westendorp RG, et al. Genetic variation in galectin-3 gene associates with cognitive function at old age. Neurobiol Aging. (2012) 33:2232. doi: 10.1016/j.neurobiolaging.2012.05.001

26. Wang X, Zhang S, Lin F, Chu W, Yue S. Elevated galectin-3 levels in the serum of patients with Alzheimer's disease. Am J Alzheimers Dis Other Demen. (2015) 30:729-32. doi: 10.1177/1533317513495107

27. Dinarello CA. Immunological and inflammatory functions of the interleukin-1 family. Annu Rev Immunol. (2009) 27:519-50. doi: 10.1146/annurev.immunol.021908.132612

28. Lu J, Kang J, Zhang C, Zhang X. The role of IL-33/ST2L signals in the immune cells. Immunol Lett. (2015) 164:11-7. doi: 10.1016/j.imlet.2015.01.008

29. Mueller T, Jaffe AS. Soluble ST2 - analytical considerations. Am. J. Cardiol. (2015) 115(7 Suppl):8B-21. doi: 10.1016/j.amjcard.2015.01.035

30. Miller AM, Xu D, Asquith DL, Denby L, Li Y, Sattar N, et al. IL-33 reduces the development of atherosclerosis. J. Exp. Med. (2008) 205:339-46. doi: $10.1084 /$ jem.20071868

31. Dieplinger B, Mueller T. Soluble ST2 in heart failure. Clin. Chim. Acta. (2015) 443:57-70. doi: 10.1016/j.cca.2014.09.021

32. Pencic-Popovic B, Sljivic A, Lopez-Andres N, Roy I, Escribano E, Beunza $\mathrm{M}$, et al. Soluble ST2 levels and left ventricular structure and function in patients with metabolicsyndrome. Ann. Lab. Med. (2016) 36:542-9. doi: $10.3343 / \mathrm{alm} .2016 .36 .6 .542$

33. Wicher G, Husic E, Nilsson G, Forsberg-Nilsson K. Developmental expression of IL-33 in the mouse brain. Neurosci Lett. (2013) 555:171-6. doi: 10.1016/j.neulet.2013.09.046

34. Chapuis J, Hot D, Hansmannel F, Kerdraon O, Ferreira S, Hubans C, et al. Transcriptomic and genetic studies identify IL-33 as a candidate gene for Alzheimer's disease. Mol. Psychiatry. (2009) 14:1004-16. doi: $10.1038 / \mathrm{mp} .2009 .10$

35. Kordi-Tamandani DM, Bahrami AR, Sabbaghi-Ghale-No R, Soleimani H, Baranzehi T. Analysis of IL-33 gene polymorphism (rs11792633 C/T) and risk of schizophrenia. Mol. Biol. Res. Commun. (2016) 5:45-8.

36. De Campos-Carli SM, Miranda AS, Dias IC, de Oliveira A, Cruz BF, Vieira ÉL, et al. Serum levels of interleukin-33 and its soluble form receptor (sST2) are associated with cognitive performance in patients with schizophrenia. Compr. Psychiatry (2017) 74:96-101. doi: 10.1016/j.comppsych.2017.01.008

37. Borovcanin M, Jovanovic I, Radosavljevic G, Djukic Dejanovic S, Bankovic $\mathrm{D}$, Arsenijevic N, et al. Elevated serum level of type-2 cytokine and low IL-17 
in first episode psychosis and schizophrenia in relapse. J Psychiatr Res. (2012) 46:1421-6. doi: 10.1016/j.jpsychires.2012.08.016

38. Borovcanin M, Jovanovic I, Radosavljevic G, Djukic Dejanovic S, Stefanovic V, Arsenijevic N, et al. Antipsychotics can modulate the cytokine profile in schizophrenia: attenuation of the type-2 inflammatory response. Schizophr Res. (2013) 147:103-9. doi: 10.1016/j.schres.2013.03.027

39. Borovcanin M, Jovanovic I, Dejanovic SD, Radosavljevic G, Arsenijevic $\mathrm{N}$, Lukic ML. Increase systemic levels of IL-23 as a possible constitutive marker in schizophrenia. Psychoneuroendocrinology (2015) 56:143-7. doi: 10.1016/j.psyneuen.2015.03.003

40. World Health Organization. International Statistical Classification of Diseases and Related Health Problems Tenth Revision. Geneva:World Health Organization (1992).

41. Kay SR, Opler LA, Fiszbein A. Positive and Negative Syndrome Scale Manual. North Tonawanda, NY: Multi-Health Systems (1994).

42. Van Os J, Burns T, Cavallaro R, Leucht S, Peuskens J, Helldin L, et al. Standardized remission criteria in schizophrenia. Acta Psychiatr Scand. (2006) 113:91-5. doi: 10.1111/j.1600-0447.2005.00659.x

43. Zuberi RI, Hsu DK, Kalayci O, Chen HY, Sheldon HK, Yu L, et al. Critical role for galectin-3 in airway inflammation and bronchial hyperresponsiveness in a murine model of asthma. Am J Pathol. (2004) 165:2045-53. doi: 10.1016/S0002-9440(10)63255-5

44. Liu FT, Hsu DK. The role of galectin-3 in promotion of the inflammatory response. Drug News Perspect. (2007) 220:455-60. doi: 10.1358/dnp.2007.20.7.1149628

45. Lee AF, Chen HY, Wan L, Wu SY, Yu JS, Huang AC, et al. Galectin-3 modulates Th17 responses by regulating dendritic cell cytokines. Am J Pathol. (2013) 183:1209-22. doi: 10.1016/j.ajpath.2013.06.017

46. Chen YH, Lee HC, Lin HC. Prevalence and risk of atopic disorders among schizophrenia patients: a nationwide population based study. Schizophr. Res. (2009) 108:191-6. doi: 10.1016/j.schres.2008.12.021

47. Pedersen MS, Benros ME, Agerbo E, Børglum AD, Mortensen PB. Schizophrenia in patients with atopic disorders with particular emphasis on asthma: a Danish population-based study. Schizophr. Res. (2012) 138:58-62. doi: 10.1016/j.schres.2012.02.019

48. Kajitani K, Yanagimoto K, Nakabeppu Y. Serum galectin-3, but not galectin-1, levels are elevated in schizophrenia: implications for the role of inflammation. Psychopharmacology (2017) 234:2919-27. doi: 10.1007/s00213-017-4683-9

49. Kurowska-Stolarska M, Kewin P, Murphy G, Russo RC, Stolarski B, Garcia CC, et al. IL-33 induces antigen-specific IL-51 T cells and promotes allergicinduced airway inflammation independent of IL-4. J Immunol. (2008) 181:4780-90. doi: 10.4049/jimmunol.181.7.4780

50. Xu D, Jiang HR, Kewin P, Li Y, Mu R, Fraser AR, et al. IL-33 exacerbates antigen-induced arthritis by activating mast cells. Proc Natl Acad Sci USA. (2008) 105:10913-8. doi: 10.1073/pnas.0801898105

51. Jovanovic IP, Pejnovic NN, Radosavljevic GD, Pantic JM, Milovanovic $\mathrm{MZ}$, Arsenijevic NN, et al. Interleukin-33/ST2 axis promotes breast cancer growth andmetastases by facilitating intratumoral accumulation of immunosuppressiveand innate lymphoid cells. Int J Cancer (2014) 134:1669-82. doi: 10.1002/ijc.28481

52. Jovanovic IP, Pejnovic NN, Radosavljevic GD, Arsenijevic NN, Lukic ML. IL33/ST2 axis in innate and acquired immunity to tumors. Oncoimmunology (2012) 1:229-31. doi: 10.4161/onci.1.2.18131

53. Liew FY, Girard JP, Turnquist HR. Interleukin-33 in health and disease. Nat. Rev. Immunol. (2016) 16:676-89. doi: 10.1038/nri.2016.95

54. Jiang HR, Milovanović M, Allan D, Niedbala W, Besnard AG, Fukada S, et al. IL-33 attenuates EAE by suppressing IL-17 and IFN- $\gamma$ production and inducing alternatively activated macrophages. Eur J Immunol. (2012) 42:1804-14. doi: 10.1002/eji.201141947

55. Fu AK, Hung KW, Yuen MY, Zhou X, Mak DS, Chan IC, et al. IL-33 ameliorates Alzheimer's disease-like pathology and cognitive decline. Proc Natl Acad Sci USA. (2016) 113:E2705-13. doi: 10.1073/pnas.1604032113
56. Lamkanfi M, Dixit VM. IL-33 raises alarm. Immunity (2009) 31:5-7. doi: 10.1016/j.immuni.2009.06.011

57. Momen T, Ahanchian H, Reisi M, Shamsdin SA, Shahsanai A, Keivanfar M. Comparison of interleukin-33 serum levels in asthmatic patients with a control group and relation with the severity of the disease. Int J Prev Med. (2017) 8:65. doi: 10.4103/ijpvm.IJPVM_179_16

58. Pejnovic N, Jeftic I, Jovicic N, Arsenijevic N, Lukic ML. Galectin-3 and IL-33/ST2 axis roles and interplay in diet-induced steatohepatitis. World $J$ Gastroenterol. (2016) 22:9706-17. doi: 10.3748/wjg.v22.i44.9706

59. Mueller T, Dieplinger B. Soluble ST2 and galectin-3: what we know and don't know analytically. EJIFCC (2016) 27:224-37.

60. Yancy CW, Jessup M, Bozkurt B, Butler J, Casey DEJr, Colvin MM, et al. 2017 ACC/AHA/HFSA focused update of the 2013 ACCF/AHA guideline for the management of heart failure: a report of the American College of Cardiology/American Heart Association Task Force on Clinical Practice Guidelines and the Heart Failure Society of America. J Card Fail. (2017) 23:628-51. doi: 10.1016/j.cardfail.2017.04.014

61. Crump C, Winkleby MA, Sundquist K, Sundquist J. Comorbidities and mortality in persons with schizophrenia: a Swedish national cohort study. Am J Psychiatry (2013) 170:324-33. doi: 10.1176/appi.ajp.2012.120 50599

62. Sweeting J, Duflou J, Semsarian C. Postmortem analysis of cardiovascular deaths in schizophrenia: a 10-year review. Schizophr Res. (2013) 150:398-403. doi: 10.1016/j.schres.2013.08.029

63. Davidson M. Risk of cardiovascular disease and sudden death in schizophrenia. J Clin Psychiatry. (2002) 63(Suppl. 9):5-11. Review. Erratum in: J. Clin. Psychiatry. (2002) 63:744.

64. Baumeister D, Akhtar R, Ciufolini S, Pariante CM, Mondelli V. Childhood trauma and adulthood inflammation: a meta-analysis of peripheral C-reactive protein, interleukin-6 and tumour necrosis factor- $\alpha$. Mol Psychiatry (2016) 21:642-9. doi: 10.1038/mp.2015.67

65. Negi N, Das BK. CNS: Not an immunoprivilaged site anymore but a virtual secondary lymphoid organ. Int Rev Immunol. (2017) 37:57-68. doi: 10.1080/08830185.2017.1357719.

66. Greenhalgh AM, Gonzalez-Blanco L, Garcia-Rizo C, Fernandez-Egea E, Miller B, Arroyo MB, et al. Meta-analysis of glucose tolerance, insulin, and insulin resistance in antipsychotic-naïve patients with nonaffective psychosis. Schizophr Res. (2017) 179:57-63. doi: 10.1016/j.schres.2016. 09.026

67. Misiak B, Stanczykiewicz B, Łaczmanski Ł, Frydecka D. Lipid profile disturbances in antipsychotic-naive patients with first-episode nonaffective psychosis: Authors' reply. Schizophr. Res. (2017) 192:471-2. doi: 10.1016/j.schres.2017.04.032

68. Weinberger DR. The neurodevelopmental origins of schizophrenia in the penumbra of genomic medicine. World Psychiatry (2017) 16:225-6. doi: 10.1002/wps.20474

69. Song X, Fan X, Li X, Zhang W, Gao J, Zhao J, et al. (2014). Changes in pro-inflammatory cytokines and body weight during 6-month risperidone treatment in drug naïve, first-episode schizophrenia. Psychopharmacology 231:319-25. doi: 10.1007/s00213-013-3382-4

Conflict of Interest Statement: The authors declare that the research was conducted in the absence of any commercial or financial relationships that could be construed as a potential conflict of interest.

Copyright (C) 2018 Borovcanin, Janicijevic, Jovanovic, Gajovic, Arsenijevic and Lukic. This is an open-access article distributed under the terms of the Creative Commons Attribution License (CC BY). The use, distribution or reproduction in other forums is permitted, provided the original author(s) and the copyright owner are credited and that the original publication in this journal is cited, in accordance with accepted academic practice. No use, distribution or reproduction is permitted which does not comply with these terms. 